\title{
Cuidados Paliativos na Formação do Profissional da Área de Saúde
}

\author{
Palliative Care in the Formation of Health \\ Care Professionals
}

Anelise Fonsecal Fatima Geovanini ${ }^{I}$

\author{
PALAVRAS-CHAVE: \\ - Cuidados Paliativos; \\ - Ensino Médico; \\ - Morte; \\ - Finitude; \\ - Habilidades Técnicas.
}

\section{KEYWORDS:}

- Palliative Care;

- Medical Education;

- Death;

- End of Life;

- Technical Skills.

Aprovado em: 07/01/2013

\section{RESUMO}

Os cuidados paliativos formam um conjunto de intervenções aplicadas em doenças quando não há perspectiva de cura e exigem um conhecimento do médico que ultrapassa o controle de sinais e sintomas. O desenvolvimento desta área do cuidado no Brasil tornou-se evidente nos últimos dez anos e culminou com o reconhecimento da especialidade médica em 2011. Falar sobre morte na graduação implica abordar o treinamento em habilidades como comunicação, trabalho em equipe e suporte à família, além do controle de sinais e sintomas, para que se possa oferecer cuidados ao final de vida com qualidade e minimizar o sofrimento de quem enfrenta a fase de terminalidade da doença. A inclusão dos cuidados paliativos na graduação do ensino médico é uma opção a ser discutida nos currículos atuais para que se possa estimular a capacidade técnica especializada nesta área do saber e difundir as técnicas de cuidado para qualquer especialidade médica.

Palliative care form a set of interventions applied to diseases when there is no prospect of cure, and requires a doctor's knowledge which goes beyond the control of signs and symptoms. The development of this area of care in Brazil became evident in the last 10 years and culminated in the recognition of the medical specialty in 2011. Talking about death in medical school should be linked to training in skills such as communication, team work and support for the family, beyond the control of signs and symptoms so that it may be offered quality care at the end of life and minimized the suffering of those facing a terminal phase of disease. The inclusion of palliative care in undergraduate medical education is an option to be discussed in current curricula so that we can stimulate not only the expertise in this specialized area of knowledge, but also to spread the techniques of care for any medical specialty. 


\section{INTRODUÇÃO}

Os cuidados paliativos (CP) são medidas de conforto oferecidas por uma equipe de saúde com o objetivo de amenizar sintomas desagradáveis e até incapacitantes, como dor, dispneia e constipação, provocados pela progressão de uma doença e/ ou por seu tratamento. O termo, cunhado em 1974 pelo canadense Balfour Mount, deriva do latim pallium ("manta"), que remete à ideia de proteger ou amparar. Na prática, correspondem às intervenções na saúde global do doente realizadas por uma equipe multidisciplinar composta por profissionais das ciências da saúde, sociais e humanas que atuam em diversas esferas, desde o domicílio até a internação em instituições como hospitais, longa permanência e o hospice, um local considerado específico para esse tipo de cuidado ${ }^{1,2}$. Os cuidados paliativos são destinados a pacientes portadores de neoplasias e outras doenças crônico-degenerativas - como demências, doença de Parkinson, insuficiência cardíaca, insuficiência renal e doença pulmonar obstrutiva crônica essencialmente quando não há perspectiva de cura. Trata-se de um modelo de cuidado cujo foco de atenção é deslocado da doença para a pessoa doente, em sua história de vida e contexto familiar e em seu processo de adoecimento e morte, proporcionando a todos os envolvidos conforto psicológico, social e espiritual ${ }^{3,4}$

O movimento dos cuidados paliativos no Brasil, como filosofia de trabalho, deu-se no início na década de 1980 com os primeiros serviços instituídos no Rio Grande do Sul, São Paulo e Santa Catarina. No Rio de Janeiro, localiza-se o Hospital do Câncer IV, do Instituto Nacional do Câncer, que funciona desde 1989 especificamente para os CP nas modalidades de atendimento ambulatorial, internação hospitalar e assistência domiciliar e é referência nacional no ensino e capacitação de profissionais para o atendimento em cuidados paliativos. Em 2005, um grupo de médicos de diferentes áreas de atuação, como Geriatria, Pediatria, Oncologia e Medicina de Família, fundou a Academia Nacional de Cuidados Paliativos (ANCP), cujo mote principal é o esclarecimento, a divulgação e a promoção dos CP no Brasili5, . Este movimento foi crescendo e se ampliando, levando o Conselho Federal de Medicina (CFM) a criar a Câmara Técnica sobre a Terminalidade da Vida. Em 2006, foi criada a Resolução $n^{\circ} 1.805 / 2006$, então polêmica e ao mesmo tempo um marco em relação à legislação dos cuidados paliativos no Brasil, contribuindo decisivamente para a aprovação da medicina paliativa como especialidade médica em dezembro de 2011, diferentemente de outros países, como Inglaterra, EUA e Irlanda, onde a medicina paliativa foi reconhecida nas décadas de 1980 e 1990. Atualmente, no Brasil, há um centro formador de médicos paliativistas em Santa Catari- na, onde o residente em Clínica Médica tem a opção de realizar seu terceiro ano na medicina paliativa ${ }^{7}$. Além disso, o Ministério da Educação (MEC), pela Resolução CNE/CES n 01 de 08/06/2007, certifica cursos de extensão de CP para outras áreas de atuação na modalidade de pós-graduação lato sensu. Nesta realidade, os cursos de capacitação são esparsos e ainda há resistências ao debate sobre o assunto, reforçando a ideia de que somente com uma mudança substancial na gestão do conhecimento e nos currículos de graduação dos profissionais de saúde é que os $\mathrm{CP}$ terão a oportunidade de se consolidar no Brasil ${ }^{8}$.

A formação do profissional em medicina paliativa deve desenvolver, entre outras, as habilidades de comunicação, o trabalho em equipe, a competência na condução diante da doença em estágio terminal e o manejo de drogas especificas, como analgésicos, reguladores intestinais, sedativos e antipsicóticos, além das técnicas de suporte, de enfrentamento da morte e do luto que pacientes, familiares e profissionais necessitam. Kovács ${ }^{9}$, ao falar sobre a educação para a morte, verifica que os profissionais, ao cuidarem de pacientes próximos da morte, para não estabelecer vínculos mais estreitos, realizam suas atividades de maneira rotineira, superdimensionando os aspectos técnicos. A autora afirma que o despreparo dos profissionais para lidar com a morte tem como causas questões culturais e espirituais e o ensino na área de saúde, que enfatiza a formação técnico-científica em detrimento da abordagem dos aspectos emocionais, espirituais e sociais. Nesse sentido, muitas vezes, a morte pode ser percebida como derrota, uma frustração pessoal que transcende a limitação técnica. Figueredo $^{10}$ é outro autor envolvido com a educação dos profissionais de saúde em CP. Interessou-se pelo tema em 1992, quando na unidade hospitalar conheceu enfermeiras que se dedicavam ao trabalho de aliviar e consolar doentes e observou que os médicos resistiam aos CP. Em 1994, inseriu um curso de CP multiprofissional, extracurricular, com o apoio dos alunos e, em 1998, elaborou a disciplina eletiva de CP juntamente com o ambulatório de CP na mesma escola médica. Elementos contribuintes dessa transformação a favor da educação em CP emergem do interesse dos profissionais envolvidos, essencialmente da área assistencial de saúde, por vivenciarem diariamente as dificuldades do processo de morrer.

O tema morte é um assunto abordado com comedimento, visto que nossa sociedade demonstra dificuldades em aceitar a finitude. No campo da saúde, os profissionais que lidam diariamente com a morte deveriam receber estímulo e auxílio para uma reflexão sobre o tema e capacitação técnica que os habilite a assumir suas responsabilidades diante da morte dos pacientes ${ }^{11}$. Azeredo, por meio da análise de questionários 
aplicados a estudantes de Medicina, aponta o medo, a impotência e o desprezo pela morte como três características presentes e indica a necessidade de ampliar os espaços de discussão para aproximar a "morte e o morrer" da formação médica. Esse autor acrescenta que os próprios alunos desejavam ter em sua formação uma oportunidade de repensar suas emoções ${ }^{12}$. Por fim, Moritz discutiu a postura dos médicos perante a morte afirmando que a meta de salvar vidas está enraizada na formação médica. Consequentemente, a morte acaba sendo encarada como temerosa, e os médicos procuram evitá-la a todo e qualquer custo ${ }^{13}$. Isto vem se refletindo na condução clínica dos pacientes em fase terminal de doença, como apontado em 2010 pela revista de economia inglesa The Economist. Este periódico publicou um ranking de qualidade de morte no qual o Brasil, segundo os critérios escolhidos, foi alocado como o terceiro pior país para se morrer, e um dos motivos seria a ausência de cuidados paliativos na graduação dos profissionais de saúde, essencialmente dos médicos ${ }^{14}$. Diante destes apontamentos, surgem algumas questões: como os médicos estão sendo formados para enfrentar a morte no seu dia a dia de trabalho? Será que recebem algum tipo de preparação? Os CP estão inseridos nos cursos de graduação de Medicina?

A educação na saúde, principalmente na Medicina, deve se propor a acompanhar essas mudanças, buscando formar profissionais com embasamento biotecnológico e humanitário condizente com essa nova realidade. Tradicionalmente, o ensino médico está fundamentado no treinamento técnico-científico; no entanto, segundo Eksterman ${ }^{15}$, este não deve suplantar o conhecimento dos aspectos relacionais inerentes ao encontro humano que se dá entre o médico e o paciente, encontro esse que deve ser o substrato indispensável de qualquer ação terapêutica. Nos cuidados paliativos, médicos e pacientes se encontram inseridos em um contexto de forte conteúdo afetivo-emocional, desencadeado pelas situações limítrofes de vida e morte comumente enfrentadas. Essas experiências podem trazer à tona questões de difícil manejo para o médico, evidenciando suas dificuldades para lidar com a morte. O limite que a morte revela ao médico enquanto impossibilidade terapêutica para a manutenção da vida gera um sentimento de impotência e medo do fracasso. De acordo com Nuland ${ }^{16}$, a medicina está entre as profissões que apresentam mais chance de atrair pessoas com alto grau de dificuldade para lidar com a morte. $\mathrm{O}$ confronto com estas dificuldades pode acarretar sérias consequências emocionais para a vida do sujeito e para a qualidade e o desempenho de seu trabalho. Este é um fato alarmante e que merece atenção de educadores e orientadores profissionais. Entretanto, as iniciativas são tímidas e sem um direcionamento normativo.
O objetivo deste artigo é discutir as atuais iniciativas de inserção dos CP no currículo médico, apontando algumas habilidades necessárias para atuar na área, fomentando o interesse para uma pesquisa de maior extensão voltada à inserção dos CP na graduação médica.

\section{METODOLOGIA}

Para identificar a presença dos CP no currículo da graduação de profissionais da área da saúde, foi realizada uma ausculta exploratória e informal por meio da aplicação de um questionário a estudantes durante o Congresso de Geriatria e Gerontologia ocorrido em 2012, no intuito de identificar nos presentes a existência de alguma abordagem dos CP e como é a sua inserção nos cursos de graduação médica. As informações foram coletadas segundo um método qualitativo, exploratório, aplicado para ouvir opiniões a respeito de determinado tema e gerar hipóteses.

Este trabalho foi executado com a ciência e autorização do comitê organizador do Congresso, que ocorreu na cidade do Rio de Janeiro de 22 a 25 de maio de 2012, contando com 4 mil congressistas. Os questionários foram aplicados durante o fórum acadêmico, organizado com o objetivo de proporcionar uma troca de experiências entre os estudantes de graduação de todas as áreas da saúde envolvidas com o envelhecimento. Após uma breve exposição acerca dos objetivos da consulta e do preenchimento do consentimento livre e esclarecido, foi entregue um formulário (Anexo) sobre a presença dos $\mathrm{CP}$ ao longo da graduação e na rotina de trabalho. Cabe lembrar que o anonimato e o sigilo foram mantidos, não trazendo nenhum risco aos sujeitos da pesquisa. Na sala havia 17 estudantes, potenciais participantes, cientes de que se tratava de uma pesquisa informal. Após o preenchimento do questionário, foi exibido o filme $O$ médico, produzido pelo Conselho Federal de Medicina, com texto de Rubem Alves. O objetivo foi sensibilizar os alunos para o trabalho do médico, correlacionando a morte ao seu papel como profissional e como uma pessoa que lida com o sofrimento humano.

\section{RESULTADOS}

Dentre os 17 participantes, sete eram estudantes de Medicina, um aluno de doutorado em Geriatria e um não se identificou; a média de idade era de 27 anos; cinco alunos pertenciam a escolas com financiamento privado. $\mathrm{Na}$ questão conceitual sobre $\mathrm{CP}$, nenhum dos presentes citou a definição da Organização Mundial de Saúde; quatro nada escreveram sobre o que sabiam, e o restante do grupo demonstrou ter alguma noção sobre o tema abordado pelo formulário. Seis participantes obtiveram os CP na graduação: um no quinto ano, um na disci- 
plina de Oncologia, no quarto ano, dois em disciplinas de Geriatria/Gerontologia, no segundo e quarto anos da graduação, dois com uma disciplina especifica de CP no quarto ano. Desse total, dois apontaram que o médico foi um profissional de relevância e outros dois apontaram o psicólogo como profissional-chave deste contato. Quando se questionou se haviam tido a oportunidade de discutir o tema de CP na rotina de trabalho, apenas seis responderam que sim, sendo que um apontou a disciplina de Oncologia como o local para esta discussão, um em residência, um em hospital e um não respondeu. Quando perguntados sobre o que sentiram quando participaram de um caso de terminalidade da vida, apenas quatro afirmaram que tiveram contato prévio com este tipo de situação, 50\% afirmaram estar seguros teoricamente e duas pessoas afirmaram ter tido amparo da equipe multidisciplinar. Foram poucos os registros de comentários, mas o que chamou a atenção foi a valorização do familiar neste tipo de cuidado.

\section{DISCUSSÃO}

Atuar no campo dos $\mathrm{CP}$ exige não apenas um profundo conhecimento médico-científico, como também um constante enfrentamento da morte e de suas implicações do processo de morrer, fazendo com que os profissionais necessitem desenvolver, também, habilidades humanitárias e emocionais, comumente pouco trabalhadas nos cursos de graduação médica.

Os dados levantados com a opinião dos alunos mostram algumas iniciativas, ainda que discretas, no caminho para a introdução do ensino de CP nos cursos de graduação médica, acompanhando o movimento brasileiro de criação e estabelecimento desta especialidade. Além disso, as escassas experiências descritas nos questionários referentes às oportunidades de participação na condução de casos de finitude podem estar revelando dificuldades na percepção e identificação desta fase da vida ${ }^{9}$. A avaliação técnica precisa é de suma importância diante de um caso de terminalidade de doença, e o aprendizado se inicia na prática clínica. O direcionamento dos preceptores e professores para uma leitura focada na finitude, bem como a capacidade técnica, por meio do ensino ao longo da graduação, são determinantes para esta avaliação criteriosa. Sabe-se que o conteúdo teórico-prático voltado para os CP é amplo e exige a participação de outros profissionais ao longo do aprendizado. Por abarcarem aspectos que não se restringem à capacitação técnica do médico, como, por exemplo, o desenvolvimento das habilidades humanas, ressaltam-se neste aprendizado as questões de finitude da vida e a importância das relações aplicadas ao trabalho em equipe multiprofissional, deixando evidente a complexidade que envolve o ensino dos CP.
Ao considerar as habilidades técnicas desta área, sabe-se que a atuação de um profissional paliativista está baseada no controle de sinais e sintomas. Contudo, a presença da patologia não é desconsiderada e, assim, a proposta terapêutica dos $\mathrm{CP}$ está direcionada também ao controle dos efeitos colaterais de uma intervenção proposta no momento do diagnóstico. Para isso, espera-se do paliativista domínio em áreas como a fisiopatologia das doenças crônicas e a sobrevida, a farmacologia, os procedimentos de intervenção que possam ser lançados diante de complicações, o manejo do corpo, as técnicas de relaxamento, a valorização da comunicação, do aspecto espiritual e o trabalho em equipe. O médico deve compreender seu papel e, mais além, deve compartilhar sua conduta com outros membros da equipe, pois as ações são interdependentes.

Para cada área de atuação envolvida nos CP há um objetivo, e, para alcançá-lo, processos e normativas são estabelecidos para que se cumpra o plano de cuidados. No campo médico, partindo da premissa de que o profissional é responsável, por exemplo, pela prescrição farmacológica, espera-se dele o domínio do uso correto e assertivo das drogas e combinações necessárias ao controle de sintomas, o reconhecimento das interações e dos efeitos colaterais, a otimização das doses e o discernimento e o bom senso em relação ao tempo de início e ao uso das substâncias. Para que haja bom senso, a técnica é fundamental, pois a segurança na tomada de decisões está diretamente relacionada ao nível de conhecimento que o médico possui. Espera-se deste profissional a capacidade de agir prontamente perante sintomas como o sofrimento oriundo da dor física, da dispneia, da náusea, do delirium e da constipação, independentemente da causa. Por fim, do ponto de vista técnico, espera-se do médico a desafiante capacidade de prognosticar um ato complexo e que depende de um profundo conhecimento em fisiopatologia ${ }^{1,17}$. Para o aprimoramento pessoal, o médico deve buscar desenvolver e aprimorar as estratégias de comunicação e de enfrentamento para lidar com o sofrimento, com o processo de morte do paciente e o suporte no luto, tanto do paciente como dos familiares e da equipe. Sabe-se que a morte é um tema de difícil manejo para o ser humano, que, embora reconheça sua finitude, busca invariavelmente ao longo de sua vida evitá-la. É característico da raça humana certa incompletude para lidar com os aspectos relacionados à terminalidade da vida, revelando o eterno despreparo do ser humano para lidar com essas questões. Por este motivo, consideram-se essenciais as iniciativas que estimulem a inclusão deste tema no discurso dos profissionais. O importante é que a morte possa ser falada não apenas do ponto de vista biológico, mas também sob o aspecto humano da perda, buscando por meio dela a possibilidade de atribuir sentido à 
vida, auxiliando os profissionais no desenvolvimento de recursos internos para este tipo de enfrentamento ${ }^{11}$.

A comunicação é um item fundamental desta temática. Esta habilidade, considerada um dos pilares dos $\mathrm{CP}$, deve ser entendida como uma técnica a ser desenvolvida e aprimorada ao longo da experiência do profissional junto aos pacientes e seus familiares. Para Menezes ${ }^{4}$, um dos princípios que regem o modelo dos CP é o da comunicação aberta, fato que faz com que a comunicação se caracterize como um dos importantes pilares desta filosofia. No entanto, a comunicação em CP normalmente é permeada por notícias de cunho negativo, sendo de difícil gerenciamento tanto para quem a transmite quanto para o seu receptor. Consideram-se más notícias qualquer informação adversa que afeta a visão de futuro do doente e de seus familiares ${ }^{18}$. Comunicar más notícias tem sido considerado uma das tarefas mais difíceis da prática médica. Muitos fatores podem justificar tamanha dificuldade, dentre eles a falta de treinamento na técnica de comunicação e o medo do profissional de enfrentar as reações emocionais do paciente ${ }^{19}$. Quill e Townsend ${ }^{20}$ fizeram referências à dor vivida pelo médico em sua rotina de trabalho e apontaram a necessidade de este profissional receber suporte emocional para lidar com essas situações difíceis. Os autores afirmaram que esse suporte deve advir dos próprios colegas, individualmente ou em grupos de apoio, ou por meio de acompanhamento psicoterapêutico.

Para trabalhar este tema, experiências de sucesso estão sendo praticadas com o objetivo de treinar esta habilidade. Um projeto realizado nos Estados Unidos e no Canadá desenvolveu um programa de sensibilização e reflexão utilizando o teatro. Esta iniciativa se deu em função da necessidade de buscar metodologias diferenciadas para o ensino de habilidades interpessoais, como a comunicação, aplicadas no atendimento a pacientes com doenças terminais. Observou-se que nesses trabalhos o impacto emocional, obtido por meio de dramatizações, é capaz de despertar a atenção nos participantes para a importância dos aspectos humanos necessários ao provimento dos cuidados a esses pacientes ${ }^{21}$. No Brasil, encontram-se iniciativas nesse campo, como o Projeto Atenção ao Vínculo e Qualificação da Comunicação em Situações Difíceis da Atenção Oncológica, realizado em 2009. Este trabalho consistiu em oficinas de sensibilização e realização de grupos Balint-Paideia, cujo objetivo foi a qualificação de profissionais de saúde, especialmente médicos, para a melhoria do acolhimento, da comunicação e do vínculo terapêutico com pacientes oncológicos na rede hospitalar pública da cidade do Rio de Janeiro. Esse trabalho, uma parceria entre o Hospital do Câncer e o Hospital Israelita Albert Einstein, também utilizou o teatro como recurso para aprendizagem ${ }^{22}$.
Um aspecto que merece destaque é a forma como a equipe multiprofissional de CP trabalha em sua rotina. A disposição pessoal para uma rotina de trabalho complexa, a importância da escuta ativa entre os membros, a troca precisa de informações e o compartilhamento das responsabilidades e das dificuldades vividas pela equipe são o diferencial para ações de sucesso. Partindo da premissa de que um dos sucessos no CP é atingir o objetivo do paciente, este varia de acordo com a condição em que se encontra no momento. Uma equipe de $\mathrm{CP}$, formada por profissionais experientes e conscientes da sua contribuição, é um dos pontos fortes de um serviço de qualidade. Uma especial atenção deve ser dispensada ao aprimoramento contínuo deste tipo de trabalho, por meio da manutenção de atividades de educação contínua no formato interdisciplinar, já que esta forma de atuar também é considerada uma premissa dos CP. Dados da pesquisa de opinião apresentada neste artigo confirmam a importância da equipe, visto que dois estudantes destacaram a atuação do psicólogo como profissional-chave para a experiência vivida na condução do caso de CP.

Neste cenário, destacamos a premência do desenvolvimento de programas que, inseridos nas grades curriculares, possam contribuir para desenvolver as habilidades consideradas intrínsecas à atuação do médico no $\mathrm{CP}$, como a comunicação e o trabalho em equipe. Nesta ausculta exploratória, identificou-se, por meio dos participantes, uma presença minoritária de disciplinas referentes ao $\mathrm{CP}$ nos currículos de graduação. Como resultado, é sugestiva a falta de preparo, tanto técnico como emocional, dos profissionais para lidar com as questões limítrofes de vida e morte no ambiente hospitalar. Esse fato se torna especialmente alarmante ao se avaliarem áreas que apresentam números significativos de doenças graves e terminais, como as unidades de terapia intensiva, os serviços de Oncologia e os de Geriatria, gerando, dessa forma, maior sofrimento para os pacientes, familiares e equipe profissional.

\section{CONSIDERAÇÔES FINAIS}

O movimento dos CP no Brasil encontra-se em franco desenvolvimento. A consolidação em 2011 como especialidade médica, ocorrida cinco anos após a primeira resolução do CFM em 2006 e aprovação jurídica em 2010, corrobora esta mobilização. Um dos caminhos para fortalecer este movimento é a inserção dos CP nos cursos de graduação médica, seja em disciplinas específicas, nas quais o ensino se concentra no aprofundamento dos aspectos técnicos e humanos, ou por meio de um ensino transversal, quando os $\mathrm{CP}$ poderão ser discutidos ao longo de todo o percurso da graduação, em qualquer disciplina médica. Esta inserção pode ser considerada fundamental para a consolidação dos CP no Brasil. 
Esses formatos podem estimular a reflexão acerca da terminalidade da vida.

Acredita-se que somente por meio da educação do profissional haverá a possibilidade de formar não apenas médicos especialistas em $\mathrm{CP}$, mas aqueles que, diante de um paciente com doença avançada e terminal, tenham preparo para prestar um cuidado que ofereça conforto e tranquilidade ao doente e a sua família, colaborando para a melhoria do cenário de mortes no Brasil.

\section{REFERÊNCIAS}

1. Floriani CA. Moderno movimento hospice: fundamentos, crenças e contradições na busca da boa morte. [Tese]. Rio de Janeiro:Escola Nacional de Saúde Pública; 2009.

2. Junior WCS, Stoppler MC. Palliative care definition. In: The MedicineNet.com Doctors are proud to author. 3aed. 2008. Disponível on line www.medterms.com/script/ main/art.asp?articlekey=11867. Acesso em 28 de novembro de 2009.

3. Twycross R. Cuidados paliativos. Lisboa: Climepsi; 2003.

4. Menezes RA. Em busca da boa morte. Rio de Janeiro: Garamond; Fiocruz; 2004.

5. Caponero R. A evolução do movimento hospice. In: Pimenta CAM, Mota DDCF, Cruz DALM. (orgs.). Dor e cuidados paliativos, enfermagem, medicina e psicologia. Barueri/ São Paulo: Manole, 2006, p. 1-15.

6. Sobre ANCP, Nossa historia. Academia Nacional de Cuidados Paliativos. Disponível on line. In: http://www.paliativo.org.br/. Acesso em janeiro de 2008.

7. Universidade Federal de Santa Catarina. Hospital Universitário Polydoro Ernani São Thiago. Processo Seletivo para Médico Residente nº1/2012 [documento online]. [acesso em 5 nov. 2012]. Disponível em: http:/ / residenciamedica. ufsc.br/files/2012/09/Edital_completo_2012.pdf.

8. Resolução CNE/CES no 01 de 08/06/2007. Acesso em 04 de dezembro de 2010. http://portal.mec.gov.br/cne/arquivos/pdf/rces001_07.pdf

9. Kovács MJ. Educação para a morte. Temas e reflexões. Ed FAPESP.2003

10. Figueredo MTA, Educação em Cuidados paliativos - uma experiência brasileira.http://direitodoidoso.braslink. com/pdf/Educacao_cuidados_paliativos.pdf. Acesso em 14 de março de 2010.

11. Kuhl D. Introduction: Facing Death. In: What Dying People Want, New York, PublicAffairs, 2002, p. xv

12. Azeredo NSG; $\mathrm{O}$ acadêmico de medicina frente a morte:questões para se (re)pensar a formação. Dissertação de mestrado, UFRGS, 2007.
13. Moritz RD. Os profissionais de saúde diante da morte e do morrer. Bioética 2005 - 13(2).

14. The quality of death: Ranking end-of-life care across the world Commissioned by Lien Foundation. Economist Intelligence Unit. The Economist, Julho de 2010

15. Eksterman A.O ensino da psicologia médica. In: Mello Filho J. Identidade Médica. São Paulo: Casa doPsicólogo; 2006.

16. Nuland SB. Como morrremos: reflexões sobre o último capítulo da vida. Rio de Janeiro; Rocco; 1995.

17. Manueal de Cuidados Paliativos, Academia Nscional de Cuidados Paliativos. Orgs Carvalho RT. Parsons HÁ. Ed meridional; 2012.

18. Baile WF, buckman R, Lenzia R, Globera G, Bealea EA. Spikes-A Six-step protocol for Delivering Bad News: Aplication to the Patient with Cancer. Oncologist. 2000.

19. Diaz FG. Comunicando malas noticias em medicina: recomendaciones para hacer de La necessidad virtud. Med. Intensiva. 2006.

20. Quill T, Townsend P. Bad News: delivery, dialogue, and dilemmas. Arch. Intern. Med. 1991.

21. End-of-life Education Using the Dramatic Arts:The Wit Educational Initiative. Karl A. Lorenz, MD, MSHS, M. Jillisa Steckart, PsyD, and Kenneth E. Rosenfeld, MD. academicmedicine,vol.79,no.5/may 2004.

22. Ministério da saúde, Instituto Nacional de Câncer (Inca) e Sociedade Beneficente Israelita Brasileira Albert Einstein. Comunicação de más Notícias: compartilhando desafios na atenção à saúde. Rio de Janeiro: 2010.

ANEXO: $O$ instrumento utilizado está disponível para consulta em http://www.educacaomedica.org.br/anexos

\section{CONTRIBUIÇÃO DOS AUTORES}

Os autores contribuíram na elaboração das idéias e revisão do texto.

\section{CONFLITO DE INTERESSES}

Declarou não haver.

\section{ENDEREÇO PARA CORRESPONDÊNCIA}

Anelise Coelho da Fonseca

Escola Nacional de Saúde Pública/Fundação Oswaldo Cruz

Rua Leopoldo Bulhões, 1.480 - sala 818

Manguinhos - Rio de Janeiro

CEP 21041-210 - RJ

E-mail: anelise1976@gmail.com 